\section{Risk co-factors inducing malignant transformation of oral lichen planus: A literature review of clinical studies}

\author{
Wafaa Saleh ${ }^{1,2 *}$, Jilan M Youssef ${ }^{2}$, Fatma Ata ${ }^{2}$, Mohamed M \\ Anees $^{2}$, Seunghee $\mathrm{Cha}^{1}$ and Joseph Katz ${ }^{1}$
}

${ }^{1}$ Oral Diagnostic Sciences Department, College of Dentistry, University of Florida, 600 SW Archer Rd, PO Box 100416, Gainesville, FI 32610-4116,USA

${ }^{2}$ Oral Medicine and Periodontology Department, Faculty of Dentistry, Mansoura University, Elgomhouria Street, Mansoura City-35516, Egypt

\section{Abstract}

Oral lichen planus (OLP) is an autoimmune chronic inflammatory disease. The potential risk of malignant transformation in OLP remains controversial. The aim of the present study was to review original clinical studies published in indexed databases, which assessed the potential risk cofactors which were implicated in the malignant transformation of oral lichen planus. We focused our search to include most of the studies that reported malignant transformation of oral lichen planus using different combinations of the following key indexing terms: oral lichen planus, malignant transformation, smoking, alcohol, chronic inflammation, candida, human papillomavirus (HPV), hepatitis $\mathrm{C}$ virus (HCV) and immunosuppression. The animal studies were excluded from our study. Despite a dearth of studies on this topic we have identified consumption of tobacco and/or alcohol, the presence of erosive and/or atrophic areas, infection with candida, HCV, HPV, and immunosuppression as significant cofactors. Patients with OLP with these risk co-factors are at risk of malignant transformation should, therefore be followed up for an extensive period or even for life.

\section{More Information}

*Address for Correspondence: Wafaa Saleh, Oral Diagnostic Sciences Department, College of Dentistry, University of Florida. 1600 SW Archer Rd, PO Box 100416, Gainesville, FI 326104116, USA, \& Oral Medicine and periodontology Department, Faculty of Dentistry, Mansoura University, Egypt, Email: wafaasaid@mans.edu.eg

Submitted: September 26, 2021

Approved: October 13, 2021

Published: October 14, 2021

How to cite this article: Saleh W, Youssef JM, Ata F, Anees MM, Cha S, et al. Risk co-factors inducing malignant transformation of oral lichen planus: A literature review of clinical studies. J Clin Adv Dent. 2021; 5: 005-011.

DOI: 10.29328/journal.jcad.1001024

ORCiD: orcid.org/0000-0003-4143-7084

Copyright: $\odot 2021$ Saleh W, et al. This is an open access article distributed under the Creative Commons Attribution License, which permits unrestricted use, distribution, and reproduction in any medium, provided the original work is properly cited.

Keywords: Oral lichen planus; Malignant transformation; Squamous cell carcinoma

(A) Check for updates

OPEn Access

\section{Introduction}

Lichen planus is a chronic mucocutaneous inflammatory disease detected in $1 \%-2 \%$ of the general population. It is common in females more than males especially over 40 years old [1]. About $0.5 \%$ to $2 \%$ of the general population suffers from OLP which can present in many forms as reticular, papular, plaque, atrophic, and erosive types. The latter two types are the most symptomatic which carry the risk of malignant transformation (MT) [2-4].

The etiology of lichen planus is unknown, and its pathogenesis still needs more studies. It is known as an autoimmune disorder mediated by T-lymphocytes [5]. Several hypotheses were reported regarding the etiopathogenesis of OLP. The most common causes are cell-mediated immune response through T-lymphocytes and chronic inflammation. Besides, Microbial agents as fungal and viral infections as well as psychological stress were also implicated in OLP $[6,7]$.

Many studies reported MT of OLP into squamous cell carcinoma (SCC) [4,8]. Some authors consider OLP as potentially malignant disease despite its MT is controversial and data are less extensive about the risk factor of MT [9].

MT of OLP with epithelial dysplasia as histological evidence can occur at any age $[4,10]$. Several studies measured the incidence of MT of OLP into oral squamous cell carcinoma (OSSC). It was ranged from $0 \%$ [11] to $10 \%[8,11,12]$. Several pathogenic mechanisms were assumed to clarify the relation between malignancy and OLP. They include chronic inflammation [13], free radicals released in inflamed tissues, inflammatory mediators that affect survival and mutations of cells and some of the growth factors $[13,14]$.

The progression from premalignant lesions to OSCC is a chronic, complex, multistep process with gene mutation and changes of protein expression of genes causing abnormal cell growth [15]. To our knowledge, this is the first review discussing the possible detected risk co-factors involved in MT of OLP. MT of OLP remains a controversial question in the literature. 


\section{Methods}

We included the articles published until the search dates; papers written in English; studies that presented the words "OLP" and "the risk factors of malignant transformation of OLP in their titles, abstracts, or keywords; and observational studies evaluating the association between OLP and those risk factors. Using scientific databases (Scopus, PubMed, and Science Direct), a literature search was conducted between December 2019 and August 2020 to include only the clinical studies of OLP.

\section{Results and discussion}

In an attempt to identify and analyze the possible risk factors of that might induce the malignant transformation of OLP in the available scientific evidence in the literature to answer the research question. We have identified the following factors:

\section{Smoking and alcohol}

Smoking is categorized as the major risk factor of oral cancer [16]. Stimulation of carcinogenesis through smoking was attributed to the presence of three pre-carcinogenic components which are nitrosamines, benzopyrenes and aromatic amines. These chemicals induce carcinogenesis through the production of oxidative enzymes, which cause the final product to be poor in electrons and bond covalently with DNA, producing an adduct mutated region [17]. Furthermore, alcohol acts in harmony with tobacco smoking in causing oral cancer. Alcohol can induce oral carcinogenesis through atrophying oral epithelium and increasing permeability of epithelial cells. Furthermore, it can dissolve lipid components of oral mucosa as well as it can interfere with the synthesis and repair of DNA. It was reported that alcohol has a genotoxic and mutagenic effect and its chronic use can impair innate as well as acquired immunity resulting in increased susceptibility to infections and neoplasms [18].

Many studies of OLP reported smoking and alcohol consumption among their studied population. Aghbari, et al. reported a significant increase of OLP MT among smokers and alcoholics in comparison to nonsmokers and non-alcoholic OLP patients [19]. Recently, Gonzalez-Moles, et al. studied the possible risk factors of OLP MT and they found that tobacco and alcohol consumption were associated with a significantly higher risk of MT in OLP patients in comparison to the controls $(p=0.002)[4]$.

Some authors listed Smoking and alcohol as exclusion criteria of MT in OLP patients [20]. However, Gonzalez-Moles et al didn't agree with that. They suggested that smoking and alcohol may potentiate the MT risk of OLP and oral lichenoid lesions (OLLs) in individual patients [9,21], and there could be a summative oncogenic effect (tobacco and alcohol plus OLP, OLLs) as reported for other oral potentially malignant diseases (e.g, leukoplakia) [21].

\section{Chronic inflammation}

The association of chronic inflammation with a variety of epithelial malignancies has been documented in the literature [22]. OLP is a chronic inflammatory disorder and it was used by researchers as a unique disease model to study the correlation between chronic inflammation and cancer. Liu, et al. considered OLP as a pure inflammatory disorder in which chronic inflammation predisposes the lesion to MT [23]. These findings proposed that the immunosuppression triggered by chronic inflammation enhances carcinogenesis in OSCC, instead of initiating it [24]. So, inflammatory cellular infiltration in oral tissues was reported as a strong risk factor for oral cancer by many studies $[22,23]$.

Interestingly, atrophic and erosive OLP lesions were reported to have a higher rate of MT $(3.5 \%-4.0 \%)$ than non-atrophic and non-erosive lesions $(0.5 \%)$ under the same follow-up period [25]. Canto, et al. showed the greater incidence of MT in OLP was detected in the atrophic, ulcerated and erosive types and the most common site was tongue [26]. Moreover, Agha-Hosseini, et al. found that the highest rate of malignancy was observed in atrophic and erosive lesions [27]. Most recently, Gonzalez-Moles, et al. reported that the high MT of OLP was detected in erosive and atrophic lesions while reticular lesions have no risk of MT. Thus, the authors recommended follow up of OLP patients should focus on atrophic-erosive rather than the reticular ones [4].

Additionally, Mignogna, et al. suggested that the OLPrelated Inflammation may not only be able to initiate MT in normal oral mucosa, but also it may act as a co-factor toward the molecular changes caused by environmental carcinogens, as alcohol and tobacco [22]. Furthermore, the cell cycle may be affected by certain proteins generated by inflammatory cells resulting in mutagenesis and tumor formation [28].

Chronic inflammation can enhance MT of OLP through oxidative stresses and also it can lead to the release of inflammatory cytokines, which then activate transcription factors in premalignant cells $[13,29]$. Considering OLP as a pure inflammatory disorder necessitates OLP patients to be meticulously controlled over time in order to allow the chance for the early detection of a possible malignancy.

\section{Human papilloma viruses}

Human papilloma viruses (HPVs) are circular doublestranded DNA viruses. About 170 subtypes of HPVs were detected in oral mucosa as well as other sites [30].

HPV16 and 18 were found to be strongly associated with oral premalignant lesions, especially OLP [31,32]. Pol, et al. reported that OLP lesions have a higher percentage of HPV16 and HPV18 in comparison to the normal population. In addition, they found that about $70 \%$ of OLP patients showed HPV16 positivity while all the controls were negative [31]. 
Human papilloma viruses (HPV 16, HPV 18) are not only detected in OLP lesions but also could contribute to their MT [33]. Mattila, et al. detected HPV DNA in $15.9 \%$ of OLP patients. Two of the five patients who developed OSCC had HPV positivity which was confirmed by static cytometry which is a sensitive tool in detecting HPV-associated changes in cellular DNA content and cellular proliferation [34].

Szarka, et al. studied the prevalence of HPV in OLP lesions with a high risk of MT (erosive and atrophic types) than low risk types (non-atrophic and non-erosive types). They reported that HPV increases the MT rate of OLP as they found that a high prevalence of HPV in OLP with a high risk of MT (42\%) than low risk OLP types (22 [25].

Since HPV related OSCCs are biologically different from non-HPV related OSCCs, it is essential to include HPV detection as a possible biomarker which can predict MT of OLP $[35,36]$. Therefore, a long-term follow up is essential. More prospective cohort studies are needed to confirm the role of HPV as an etiological agent of OLP carcinogenesis.

\section{Candida}

Association of candida with common oral lesions as OLP, leukoplakia, pemphigus vulgaris was reported in the literature. Various species of candida have been detected in OLP. Candida albicans (c. albicans), candida tropicalis (C.tropicalis), and the combination of C.albicans \& C.tropicalis were detected in OLP. [37,38]. Furthermore, C.albicans was detected in premalignant lesions as well as OSCCs $[37,39]$. Sing, et al. detected C.albicans in about $83.3 \%$ of OLP patients [37]. Kragelund, et al. reported the presence of Candida SPs in 16 of 30 patients with OLP [40]. Others reported that there was no significant difference regarding the colonization of C.albicans between reticular, atrophic and erosive forms of OLP [41].

In combination with other risk factors such as smoking and alcohol, candida was reported to have a synergistic impact. [21]. Candida Infection can induce inflammatory changes in the oral epithelium that may result in dysplastic changes [42]. Researchers' attention has been drawn to the possible association between candida species (SPs) and oral cancer. However, no enough studies were published that could support or disapprove this hypothesis.

Various biological theories were reported to favor that correlation. Candida can easily colonize and penetrate the oral mucosa and induce chronic inflammation that predisposes to neoplastic evolution [42]. The induction of carcinogenic changes by candida was reported in animal models [43]. Researchers should put into consideration if candida over infected OLP after or before OLP treatment as immunosuppressive therapy can induce candida overgrowth [44]. In addition, types of candida and resistance of candida to drugs should be reported [45].
Initial colonization of Candida SPs is in yeast form. After that, epithelium may undergo some changes due to trauma, immunosuppression or other factors resulting in more invasion of Candida into underlying connective tissue with changing into hyphae forms that produce intra-mucosal hydrolytic enzymes [46]. It was assumed that C.albicans may play a direct role in MT of OLP due to the yeast forms which are capable of producing carcinogenic enzyme $\mathrm{N}$ nitrosobenzylmethylamine [47].

Recently, the authors found that C. albicans was able to activate the TLR2/MyD88/NF-KB signaling pathway in OLP epithelial cells with increasing the expression of cytokines and decreasing keratinocyte apoptosis. The later are the two principal pathogenic factors in MT of OLP namely increased inflammation and decreased apoptosis [48].

In addition, some authors found that there was a higher correlation between the number of candida colonies and the severity of epithelial dysplasia [49]. Werneck, et al. reported that in OLP cases, nine cases had epithelial dysplasia. Cytopathological examination showed an association with candidiasis in 8 of the 21 cases [50]. Based on the previous studies, it is reasonable to suggest further studies on the role of Candida SPs in MT of OLP based on a biochemical basis through which the production of carcinogenic enzymes can be detected.

\section{Immunosuppressive therapy}

It is conceivable that, systemic immune defects may be involved in developing carcinoma in OLP patients [51]. Corticosteroids act as an immune-modulating agent which often are utilized to reduce the inflammatory response in OLP and OLLs [52]. There is still debate regarding whether utilization of corticosteroids is contraindicated in OLP and OLLs or not, as this treatment could depress local cell mediated immunity and may enhance the progression of neoplastic transformation [53].

Corticosteroids have been suggested to increase the susceptibility of patients to MT [51]. Immunosuppressive treatment may act as a cofactor to smoking and alcohol in producing oral cancer. Duffey et al reported that 5 cases of OLP patients who received topical and systemic steroid treatment developed OSCC later. Two of those patients were smokers and alcohol consumers. The authors recommended that possible avoidance of topical steroids could decrease the future incidence of OSCCs in OLP lesions [51]. Furthermore, Laeijendecker, et al. detected OSCC in three patients who had OLP and were treated with immunosuppressive drugs. One of those patients received systemic immunosuppressive medication (corticosteroids and cyclosporine) over a period of about 2 years. The authors reported that therapy could have increased the chance of developing OSCC in OLP lesions [54].

Treatment of lichenoid lesions with topical steroids 
increased the risk of HPV infection from $16 \%$ to $21 \%$. These findings could be attributed to the chronic use of topical steroids that may be associated with reactivation of the latent HPV or may promote its overexpression and may induce malignant changes $[55,56]$.

On the other hand, other studies suggested that, immunosuppressive treatment does not increase the risk of MT of OLP $[57,58]$ and may reduce it. Otero-rey, et al. reported that, low dose maintenance therapy of topical corticosteroids could inhibit the progression of OLP to OSCC as it may prevent the persistence of chronic inflammation and so inhibit MT [59]. It has been suggested that, the elevation of proinflammatory cytokines may enhance the neoplastic transformation and the use of a more aggressive immunosuppressive therapy against the associated inflammatory reaction in OLP might restore normal immunosurveillance and interfere with neoplastic progression [11].

Topical tacrolimus which is an immunosuppressive drug used for the treatment of OLP was implicated in developing oral cancer. Mattsson, et al. reported that five years after diagnosis of a patient with OLP and treatment with topical tacrolimus, the patient developed a SCC in the region where tacrolimus had been applied [60] (Figure 1). Tacrolimus was reported to induce MT by affecting cancer signaling pathway as the mitogen-activated protein kinase (MAPK) pathway and P53 [61]. Becker, et al. reported another case of recalcitrant OLP which received maintained dose of topical tacrolimus for 3 years and developed OSCC at the lateral border of the tongue [61]. Morita, et al. reported a case of OLP who applied tacrolimus ointment to the lower lip after being diagnosed with OLP in 2008, and whose lesion developed a SCC in 2010 [62]. Despite the correlation between topical tacrolimus treatment and cancer development has been documented in only a few cases, still the number of available cases and follow-

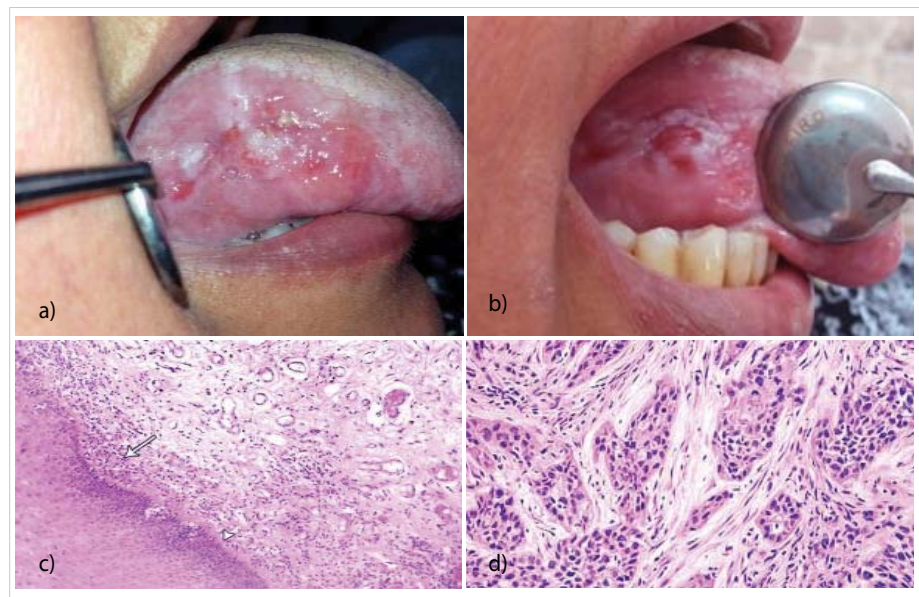

Figure 1: MT of OLP lesion on the lateral side of the tongue.

Clinical picture showing erosive type of lichen planus on the lateral surface of the right side of the tongue of 60 years old male who is smoker. b) Clinical picture of the same patients after 3 years from the first visit with indurated lesion at the lateral surface of the tongue. c) Photomicrograph of oral lichen planus lesion at the first visit showing eosinophilic band, and lymphocytic band(arrow head) (H\&E x 200). d) A Photomicrograph of the lesion after 3 years showing moderately differentiated OSCC with cell nests and moderate signs of malignancy (H\&E x 200). up period has been insufficient to draw any firm conclusions. However, the clinician must be careful in choosing tacrolimus as a second-line treatment for OLP.

\section{Hepatitis c virus}

Hepatitis c virus (HCV) was reported to elevate the chance of MT [63] and HCV replication was detected in samples taken from patients having oral cancer [64]. Positive HCV serology was reported in about $12.8 \%$ of patients with head and neck cancer [63]. A population-based cohort study performed in Taiwan reported that HCV infection alone is a risk factor for oral cancer [65]. Despite many studies reported the correlation between OSCCs and HCV detection, this association remains controversial and it would be difficult to present unequivocal or definitive conclusions [66].

Studies point out that the HCV viral capsid protein is characterized by oncogenic potential being able to act through different mechanisms such as cellular proliferation and death or chronic inflammation. In addition, HCV can induce the production of free radicals [67]. The mechanism of inducing tumorigenesis by HCV infection may involve either direct or indirect actions. The direct action is by deregulation of the cell cycle, while the indirect action is by producing cirrhosis [68]. Some HCV proteins, namely the core and the non-structural protein may deregulate the cell cycle in vitro.

Nagao, et al. studied the relation between HCV and OLP and showed that occurrence of OLP in HCV infected patients is not only related directly to the virus itself, but also to other host factors such as immunity, genetics and insulin resistance [69]. Lodi, et al. studied the correlation between OLP and HCV infection. They reported that HCV infection presented in up to $20 \%$ of OLP patients. These findings may encourage including HCV serology in evaluation and treatment plan of OLP [70]. Hepatitis c virus (HCV) infection is one of the risk factors involved in MT of OLP [51].

Gandolfo, et al. studied the role of HCV infection as a risk factor in the neoplastic transformation of OLP. They found that $44 \%$ of OLP patients who developed carcinomas were HCV positive. In addition, they reported that the relative risk of MT of OLP cases infected with HCV in comparison with HCV negative patients was $3.16(0.8-12.5)$. The authors concluded that the risk of development of oral cancer in OLP patients is increased with HCV infection [57]. Nagao, et al. reported a high rate for MT of OLP in HCV endemic areas, HCV-RNA strands were found in OLP tissues [64]. Another study reported that the percentage of HCV-positive OLP patients who developed an oral carcinoma are higher in comparison with HCV negative patients [71].

While the risk of MT in HCV positive OLP patients is indefinite, screening of all OLP patients for detection of HCV became a controversial matter [72,73]. Generally, we believe that HCV screening is recommended in countries with a high 
prevalence of HCV among the general population. In addition, the treatment intervention for HCV infection could reduce the consequences of hepatocellular carcinoma and OSCC.

\section{Conclusion}

The most critical variables in the estimation of carcinoma development in OLP are the initial diagnosis of OLP and the time between initial diagnosis and MT Symptoms aggravation and homogeneity loss of OLP lesions should be evaluated during the patients follow up visits. If those signs detected, more frequent follow up and further biopsy should be performed for early detection and monitoring of malignant changes in OLP lesions.

This research did not receive any specific grant from funding agencies in the public, commercial, or not-for-profit sectors.

\section{References}

1. Gorouhi F, Davari P, Fazel N. Cutaneous and mucosal lichen planus: a comprehensive review of clinical subtypes, risk factors, diagnosis, and prognosis. ScientificWorldJournal. 2014; 2014: 742826. PubMed: https://pubmed.ncbi.nlm.nih.gov/24672362/

2. Bardellini E, Amadori F, Flocchini $P$, Bonadeo S, Majorana A. Clinicopathological features and malignant transformation of oral lichen planus: a 12-years retrospective study. Acta Odontol Scand. 2013. 71: 834-840. PubMed: https://pubmed.ncbi.nlm.nih.gov/23116326/

3. Alrashdan MS, Cirillo N, McCullough M. Oral lichen planus: a literature review and update. Arch Dermatol Res. 2016; 308: 539-551.

PubMed: https://pubmed.ncbi.nlm.nih.gov/27349424/

4. Gonzalez-Moles MA, Ruiz-Ávila I, González-Ruiz L, Ayén A, GilMontoya JA, et al. Malignant transformation risk of oral lichen planus: A systematic review and comprehensive meta-analysis. Oral Oncol. 2019; 96: 121-130.

PubMed: https://pubmed.ncbi.nlm.nih.gov/31422203/

5. Mutafchieva MZ, Draganova-Filipova MN, Zagorchev PI, Tomov GT. Oral Lichen Planus - Known and Unknown: a Review. Folia Med (Plovdiv). 2018; 60: 528-535.

PubMed: https://pubmed.ncbi.nlm.nih.gov/31188760/

6. Farhi D, Dupin N. Pathophysiology, etiologic factors, and clinical management of oral lichen planus, part I: facts and controversies. Clin Dermatol. 2010; 28: 100-108.

PubMed: https://pubmed.ncbi.nlm.nih.gov/20082959/

7. Roopashree MR, Gondhalekar RV, Shashikanth MC, George J, Thippeswamy SH, et al. Pathogenesis of oral lichen planus--a review. J Oral Pathol Med. 2010; 39: 729-734.

PubMed: https://pubmed.ncbi.nlm.nih.gov/20923445/

8. Kaplan I, Ventura-Sharabi Y, Gal G, Calderon S, Anavi Y. The dynamics of oral lichen planus: a retrospective clinicopathological study. Head Neck Pathol. 2012; 6: 178-183.

PubMed: https://pubmed.ncbi.nlm.nih.gov/22160614/

9. Gonzalez-Moles MA, Scully C, Gil-Montoya JA, Oral lichen planus: controversies surrounding malignant transformation. Oral Dis. 2008; 14: 229-243

PubMed: https://pubmed.ncbi.nlm.nih.gov/18298420/

10. Fleskens S, Slootweg P. Grading systems in head and neck dysplasia: their prognostic value, weaknesses and utility. Head Neck Oncol. 2009; 1: 11.

PubMed: https://pubmed.ncbi.nlm.nih.gov/19432960/

11. Eisen D. The clinical features, malignant potential, and systemic associations of oral lichen planus: a study of 723 patients. J Am Acad Dermatol. 2002; 46: 207-214.

PubMed: https://pubmed.ncbi.nlm.nih.gov/11807431/

12. Mignogna MD, Muzio LL, Russo LL, Fedele S, Ruoppo E, et al. Clinical guidelines in early detection of oral squamous cell carcinoma arising in oral lichen planus: a 5-year experience. Oral Oncol. 2001; 37: 262-267. PubMed: https://pubmed.ncbi.nlm.nih.gov/11287280/

13. Georgakopoulou EA, Achtari MD, Achtaris M, Foukas PG, Kotsinas A. Oral lichen planus as a preneoplastic inflammatory model. J Biomed Biotechnol. 2012; 2012: 759626.

PubMed: https://pubmed.ncbi.nIm.nih.gov/22675259/

14. Mantovani A, Allavena P, Sica A, Balkwill F. Cancer-related inflammation. Nature. 2008; 454: 436-444.

PubMed: https://pubmed.ncbi.nlm.nih.gov/18650914/

15. Mohtasham N, Mahdavi-Shahri N, Salehinejad J, Ejtehadi H, TorabiParizi $\mathrm{M}$, et al. Detection of nucleoproteins in squamous cell carcinoma, and dysplastic and normal mucosa in the oral cavity by methyl greenpyronin staining. J Oral Sci. 2010; 52: 239-243.

PubMed: https://pubmed.ncbi.nlm.nih.gov/20587947/

16. Pearce N, Blair A, Vineis $P$, Ahrens $W$, Andersen A, et al. IARC monographs: 40 years of evaluating carcinogenic hazards to humans. Environ Health Perspect. 2015; 123: 507-514.

PubMed: https://pubmed.ncbi.nlm.nih.gov/25712798/

17. Rivera C. Essentials of oral cancer. Int J Clin Exp Pathol, 2015; 8 : 11884-1194.

PubMed: https://pubmed.ncbi.nlm.nih.gov/26617944/

18. Reidy JT, McHugh EE, Stassen LF. A review of the role of alcohol in the pathogenesis of oral cancer and the link between alcohol-containing mouthrinses and oral cancer. J Ir Dent Assoc. 2011; 57: 200-202. PubMed: https://pubmed.ncbi.nlm.nih.gov/21922995/

19. Aghbari SMH, Abushouk Al, Attia A, Elmaraezy A, Menshawy A, et al. Malignant transformation of oral lichen planus and oral lichenoid lesions: A meta-analysis of 20095 patient data. Oral Oncol. 2017; 68: 92-102. PubMed: https://pubmed.ncbi.nlm.nih.gov/28438300/

20. vander MeijEH, SchepmanKP, Smeele LE, van derWal JE, BezemerPD, et al. A review of the recent literature regarding malignant transformation of oral lichen planus. Oral Surg Oral Med Oral Pathol Oral Radiol Endod. 1999; 88: 307-310.

PubMed: https://pubmed.ncbi.nlm.nih.gov/10503859/

21. Chi AC, Day TA, Neville BW. Oral cavity and oropharyngeal squamous cell carcinoma--an update. CA Cancer J Clin. 2015. 65: 401-421. PubMed: https://pubmed.ncbi.nlm.nih.gov/26215712/

22. Mignogna MD, Fedele S, Russo LL, Muzio LL, Bucci E. Immune activation and chronic inflammation as the cause of malignancy in oral lichen planus: is there any evidence? Oral Oncol. 2004; 40: 120-130. PubMed: https://pubmed.ncbi.nlm.nih.gov/14693234/

23. Liu Y, Messadi DV, Wu H, Hu S. Oral lichen planus is a unique disease model for studying chronic inflammation and oral cancer. Med Hypotheses. 2010; 75: 492-494.

PubMed: https://pubmed.ncbi.nlm.nih.gov/20674185/

24. Sun Y, Liu N, Guan X, Wu H, Sun Z, et al. Immunosuppression Induced by Chronic Inflammation and the Progression to Oral Squamous Cell Carcinoma. Mediators Inflamm. 2016; 2016: 5715719. PubMed: https://pubmed.ncbi.nlm.nih.gov/28053372/

25. Szarka K, Tar I, Fehér E, Gáll T, Kis A, et al. Progressive increase of human papillomavirus carriage rates in potentially malignant and malignant oral disorders with increasing malignant potential. Oral Microbiol Immunol. 2009; 24: 314-318. PubMed: https://pubmed.ncbi.nlm.nih.gov/19572894/

26. Canto AM, Müller H, de Freitas RR, da Silva Santos PS. Oral lichen planus (OLP): clinical and complementary diagnosis. An Bras Dermatol. 2010. 85: 669-675.

PubMed: https://pubmed.ncbi.nlm.nih.gov/21152791/ 
27. Agha-Hosseini F, Sheykhbahaei N, SadrZadeh-Afshar MS. Evaluation of Potential Risk Factors that contribute to Malignant Transformation of Oral Lichen Planus: A Literature Review. J Contemp Dent Pract. 2016; 17: 692-701.

PubMed: https://pubmed.ncbi.nlm.nih.gov/27659090/

28. Bascones C, Gonzalez-Moles MA, Esparza G, Bravo M, Acevedo A, et al. Apoptosis and cell cycle arrest in oral lichen planus Hypothesis on their possible influence on its malignant transformation. Arch Oral Biol. 2005; 50: 873-881.

PubMed: https://pubmed.ncbi.nIm.nih.gov/16137496/

29. Rhodus NL, Cheng B, Myers S, Miller L, Ho V, et al. The feasibility of monitoring NF-kappaB associated cytokines: TNF-alpha, IL-1alpha, IL-6, and IL-8 in whole saliva for the malignant transformation of oral lichen planus. Mol Carcinog. 2005; 44: 77-82.

PubMed: https://pubmed.ncbi.nlm.nih.gov/16075467/

30. Lafaurie GI, Perdomo SJ, Buenahora MR, Amaya S, Díaz-Báez D. Human papilloma virus: An etiological and prognostic factor for oral cancer? J Investig Clin Dent. 2018; 9: e12313.

PubMed: https://pubmed.ncbi.nlm.nih.gov/29322686/

31. Pol CA, Ghige SK, Gosavi SR. Role of human papilloma virus-16 in the pathogenesis of oral lichen planus--an immunohistochemical study. Int Dent J. 2015; 65: 11-14.

PubMed: https://pubmed.ncbi.nlm.nih.gov/25256345/

32. Yildirim B, Senguven B, Demir C. Prevalence of herpes simplex, Epstein Barr and human papilloma viruses in oral lichen planus. Med Oral Patol Oral Cir Bucal. 2011; 16: e170-174.

PubMed: https://pubmed.ncbi.nlm.nih.gov/21196875/

33. Liu T, Zhang $\mathrm{H}$, Yang $\mathrm{X}$, Li X, Shi $\mathrm{Y}$, et al. Study on expression of $\mathrm{p} 16$ and human papillomavirus 16 and 18 (E6) in OLP and its malignant transformation. Pathol Res Pract. 2018; 214: 296-302.

PubMed: https://pubmed.ncbi.nlm.nih.gov/29254790/

34. Mattila R, Rautava J, Syrjänen S. Human papillomavirus in oral atrophic lichen planus lesions. Oral Oncol. 2012; 48: 980-984.

PubMed: https://pubmed.ncbi.nlm.nih.gov/22658678/

35. Agrawal N, Frederick MJ, Pickering CR, Bettegowda C, Chang K, et al Exome sequencing of head and neck squamous cell carcinoma reveals inactivating mutations in NOTCH1. Science. 2011; 333: 1154-1157. PubMed: https://pubmed.ncbi.nlm.nih.gov/21798897/

36. Giuliani M, Troiano G, Cordaro M, Corsalini M, Gioco G, et al. Rate of malignant transformation of oral lichen planus: A systematic review. Oral Dis. 2019; 25: 693-709.

PubMed: https://pubmed.ncbi.nlm.nih.gov/29738106/

37. Singh SK, Gupta A, Rajan SY, Padmavathi BN, Mamatha GP, et al. Correlation of presence of Candida and epithelial dysplasia in oral mucosal lesions. J Clin Diagn Res. 2014; 8: Zc31-305.

PubMed: https://pubmed.ncbi.nlm.nih.gov/25478443/

38. Bombeccari GP, Gianni AB, Spadari F. Oral Candida colonization and oral lichen planus. Oral Dis. 2017; 23: 1009-1010.

PubMed: https://pubmed.ncbi.nlm.nih.gov/28415152/

39. McCullough M, Jaber M, Barrett AW, Bain L, Speight PM, et al. Oral yeast carriage correlates with presence of oral epithelial dysplasia. Oral Oncol. 2002; 38: 391-393.

PubMed: https://pubmed.ncbi.nlm.nih.gov/12076705/

40. Kragelund C, Kieffer-Kristensen L, Reibel J, Bennett EP. Oral candidosis in lichen planus: the diagnostic approach is of major therapeutic importance. Clini Oral Investigations. 2013; 17: 957-965. PubMed: https://pubmed.ncbi.nlm.nih.gov/22699660/

41. Artico G, Freitas RS, Santos Filho AM, Benard G, Romiti R, et al Prevalence of Candida spp, xerostomia, and hyposalivation in oral lichen planus--a controlled study. Oral Dis. 2014; 20: e36-e41. PubMed: https://pubmed.ncbi.nlm.nih.gov/23656547/

42. Berman J, Sudbery PE. Candida Albicans: a molecular revolution built on lessons from budding yeast. Nat Rev Genet. 2002; 3: 918-30. PubMed: https://pubmed.ncbi.nlm.nih.gov/12459722/
43. O'Grady JF, Reade PC. Candida albicans as a promoter of oral mucosal neoplasia. Carcinogenesis. 1992; 13: 783-786.

PubMed: https://pubmed.ncbi.nlm.nih.gov/1586990/

44. Lodi G, Tarozzi M, Sardella A, Demarosi F, Canegallo L, et al. Miconazole as adjuvant therapy for oral lichen planus: a double-blind randomized controlled trial. $\mathrm{Br} J$ Dermatol, 2007; 156: 1336-1341. PubMed: https://pubmed.ncbi.nlm.nih.gov/17535232/

45. de Sousa LVNF, Santos VL, de Souza Monteiro A, Dias-Souza MV, Marques SG, et al. Isolation and identification of Candida species in patients with orogastric cancer: susceptibility to antifungal drugs, attributes of virulence in vitro and immune response phenotype. BMC Infect Dis. 2016; 16: 86.

PubMed: https://pubmed.ncbi.nlm.nih.gov/26905729/

46. Williams DW, Jordan RPC, Wei XQ, Alves CT, Wise MP, et al. Interactions of Candida albicans with host epithelial surfaces. J Oral Microbiol. 2013; 5.

PubMed: https://pubmed.ncbi.nIm.nih.gov/24155995/

47. Lodi G, Scully C, Carrozzo M, Griffiths M, Sugerman PB, et al. Current controversies in oral lichen planus: report of an international consensus meeting. Part 2. Clinical management and malignant transformation. Oral Surg Oral Med Oral Pathol Oral Radiol Endod. 2005; 100: 164-178. PubMed: https://pubmed.ncbi.nlm.nih.gov/16037774/

48. Liu J, Geng F, Sun $H$, Wang $X$, Zhang $H$, et al. Candida albicans induces TLR2/MyD88/NF-KB signaling and inflammation in oral lichen planus-derived keratinocytes. J infect Dev Cries. 2018; 12: 780-786. PubMed: https://pubmed.ncbi.nlm.nih.gov/31999637/

49. Hebbar PB, Pai A, Sujatha D, Mycological and histological associations of Candida in oral mucosal lesions. J Oral Sci. 2013; 55: 157-160. PubMed: https://pubmed.ncbi.nlm.nih.gov/23748455/

50. Werneck JT, de Oliveira Costa T, Stibich CA, Leite CA, Dias EP, et al. Oral lichen planus: study of 21 cases. Anais Brasileiros de Dermatologia. 2015; 90: 321-326.

PubMed: https://pubmed.ncbi.nlm.nih.gov/26131860/

51. Duffey DC, Eversole LR, Abemayor E. Oral lichen planus and its association with squamous cell carcinoma: an update on pathogenesis and treatment implications. Laryngoscope. 1996; 106: 357-362. PubMed: https://pubmed.ncbi.nlm.nih.gov/8614204/

52. Oberti L, Alberta L, Massimo P, Francesco C, Dorina L. Clinical Management of Oral Lichen Planus: A Systematic Review. Mini Rev Med Chem. 2019; 19: 1049-1059.

PubMed: https://pubmed.ncbi.nlm.nih.gov/30836913/

53. Hojo $M$, Morimoto $T$, Maluccio $M$, Asano $T$, Morimoto $K$, et al. Cyclosporine induces cancer progression by a cell-autonomous mechanism. Nature. 1999; 397: 530-534.

PubMed: https://pubmed.ncbi.nlm.nih.gov/10028970/

54. Laeijendecker R, van Joost T, Kuizinga MC, Tank B, Neumann HAM. Premalignant nature of oral lichen planus. Acta Derm Venereol. 2005; 85: 516-520.

PubMed: https://pubmed.ncbi.nlm.nih.gov/16396800/

55. Gorsky M, Epstein JB. Oral lichen planus: malignant transformation and human papilloma virus: a review of potential clinical implications. Oral Surg Oral Med Oral Pathol Oral Radiol Endod. 2011; 111: 461-464. PubMed: https://pubmed.ncbi.nlm.nih.gov/21330164/

56. von Krogh G, Dahlman-Ghozlan K, Syrjänen S. Potential human papillomavirus reactivation following topical corticosteroid therapy of genital lichen sclerosus and erosive lichen planus. J Eur Acad Dermatol Venereol. 2002; 16: 130-133.

PubMed: https://pubmed.ncbi.nlm.nih.gov/12046814/

57. Gandolfo S, Richiardi L, Carrozzo M, Broccoletti R, Carbone M, etal. Risk of oral squamous cell carcinoma in 402 patients with oral lichen planus: a follow-up study in an Italian population. Oral Oncol. 2004; 40: 77-83. PubMed: https://pubmed.ncbi.nlm.nih.gov/14662419/

58. Mignogna MD, Fedele S, Russo LL, Mignogna C, de Rosa G, et al. Field 
cancerization in oral lichen planus. Eur J Surg Oncol. 2007; 33: 383-389. PubMed: https://pubmed.ncbi.nlm.nih.gov/17084578/

59. Otero-Rey EM, Suarez-Alen F, Peñamaria-Mallon M, Lopez-Lopez J, Blanco-Carrion A. Malignant transformation of oral lichen planus by a chronic inflammatory process. Use of topical corticosteroids to prevent this progression? Acta Odontol Scand. 2014; 72: 570-577.

PubMed: https://pubmed.ncbi.nlm.nih.gov/24850508/

60. Mattsson U, Magnusson B, Jontell M. Squamous cell carcinoma in a patient with oral lichen planus treated with topical application of tacrolimus. Oral Surg Oral Med Oral Pathol Oral Radiol Endod. 2010; 110: e19-25.

PubMed: https://pubmed.ncbi.nlm.nih.gov/20610291/

61. Becker JC, Houben R, Vetter CS, Bröcker EB. The carcinogenic potential of tacrolimus ointment beyond immune suppression: a hypothesis creating case report. BMC Cancer. 2006; 6: 7 . PubMed: https://pubmed.ncbi.nlm.nih.gov/16405733/

62. Morita M, Asoda S, Tsunoda K, Soma T, Nakagawa T, et al. The onset risk of carcinoma in patients continuing tacrolimus topical treatment for oral lichen planus: a case report. Odontology. 2017; 105: 262-266. PubMed: https://pubmed.ncbi.nlm.nih.gov/27368962/

63. Rangel JB, Thuler LCS, Pinto J. Prevalence of hepatitis C virus infection and its impact on the prognosis of head and neck cancer patients. Oral Oncol. 2018; 87: 138-143.

PubMed: https://pubmed.ncbi.nlm.nih.gov/30527229/

64. Nagao Y, Sata M, Noguchi S, Seno'o T, Kinoshita M, et al. Detection of hepatitis $C$ virus RNA in oral lichen planus and oral cancer tissues. J Oral Pathol Med. 2000; 29: 259-266.

PubMed: https://pubmed.ncbi.nlm.nih.gov/10890556/

65. Su FH, Chang S, Chen P, Sung F, Huang S, et al. Positive association between hepatitis $C$ infection and oral cavity cancer: a nationwide population-based cohort study in Taiwan. PLoS One. 2012; 7: e48109. PubMed: https://pubmed.ncbi.nlm.nih.gov/23133554/

66. Fiorino S, Bacchi-Reggiani L, de Biase D, Fornelli A, Masetti M, et al.
Possible association between hepatitis $\mathrm{C}$ virus and malignancies different from hepatocellular carcinoma: A systematic review. World $\mathrm{J}$ Gastroenterol. 2015; 21: 12896-12953.

PubMed: https://pubmed.ncbi.nlm.nih.gov/26668515/

67. Koike K. The oncogenic role of hepatitis C virus. Recent Results Cancer Res. 2014; 193: 97-111.

PubMed: https://pubmed.ncbi.nlm.nih.gov/24008295/

68. Sorensen HT, Friis S, Olsen JH, Thulstrup AM, Mellemkjaer L, et al. Risk of liver and other types of cancer in patients with cirrhosis: a nationwide cohort study in Denmark. Hepatology. 1998; 28: 921-925. PubMed: https://pubmed.ncbi.nlm.nih.gov/9755226/

69. Nagao Y, Nishida N, Toyo-Oka L, Kawaguchi A, Amoroso A, et al. Genome-wide association study identifies risk variants for lichen planus in patients with hepatitis C virus infection. Clin Gastroenterol Hepatol. 2017; 15: 937-944.

PubMed: https://pubmed.ncbi.nlm.nih.gov/28065765/

70. Lodi G, Pellicano R, Carrozzo M. Hepatitis $C$ virus infection and lichen planus: a systematic review with meta-analysis. Oral Dis. 2010; 16: 601-612.

PubMed: https://pubmed.ncbi.nIm.nih.gov/20412447/

71. Carbone M, Arduino PG, Carrozzo M, Gandolfo S, Argiolas MR, et al. Course of oral lichen planus: a retrospective study of 808 northern Italian patients. Oral Dis. 2009; 15: 235-243.

PubMed: https://pubmed.ncbi.nlm.nih.gov/19222766/

72. Baccaglini L, Thongprasom K, Carrozzo M, Bigby M. Urban legends series: lichen planus. Oral Dis. 2013; 19: 128-143. PubMed: https://pubmed.ncbi.nlm.nih.gov/22788669/

73. Manomaivat T, Pongsiriwet S, Kuansuwan C, Thosaporn W, Tachasuttirut $\mathrm{K}$, et al. Association between hepatitis $\mathrm{C}$ infections in Thai patients with oral lichen planus: A case-control study. J Investig Clin Dent. 2018; 9: e12316.

PubMed: https://pubmed.ncbi.nlm.nih.gov/29345111/ 